\begin{tabular}{|l|l|}
\hline $\begin{array}{l}\text { ESCOLA DE COMUNICAÇÃO, } \\
\text { ARTES E DESIGN } \\
\text { PUCRS }\end{array}$ & $\begin{array}{l}\text { FAMECOS } \\
\text { Fídia, cultura e tecnologia } \\
\text { Revista FAMECOS, Porto Alegre, v. 27, p. 1-18, jan.-dez. } 2020 \\
\text { e-ISSN: 1980-3729 | ISSN-L: 1415-0549 }\end{array}$ \\
\hline dif https://dx.doi.org/10.15448/1980-3729.2020.1.34271
\end{tabular}

JORNALISMO

\title{
Por uma outra narrativa: jornalismo e micro-história em A mulher que alimentava
}

\author{
For another narrative: journalism and micro history in A mulher que alimentava \\ Por otra narrativa: periodismo y microhistoria en A mulher que alimentava
}

\section{Beatriz Marocco ${ }^{1}$ orcid.org/0000-0003-3914-1217 \\ bmarocco@unisinos.br}

\section{Francisco Aquinei} Timóteo Queirós ${ }^{2}$ orcid.org/0000-0001-5085-7668 aquinei@gmail.com

Recebido em: 27 mai. 2019. Aprovado em: 22 ago. 2019. Publicado em: 28 mai. 2020

\section{(c) (i)}

Artigo está licenciado sob forma de uma licença creative Commons Atribuição 4.0 Internacional.
Resumo: O corrente estudo é resultado de investigação em desenvolvimento no doutorado. Nessa direção, promove-se no artigo o diálogo entre a metodologia micro-histórica e a prática jornalística de Eliane Brum, tendo-se a reportagem "A mulher que alimentava", presente no livro O olho da rua, como catalisadora da análise. Ao adotar um percurso epistemológico a partir das margens, nota-se que os acontecimentos e fatos assumem uma dimensão social e cultural contraposta aos valores legitimados pela história social dominante. A micro-história volta-se, desse modo, para a compreensão problemática do particular. Nesse sentido, o objetivo é entender como o detalhe individual aponta para fragmentos de experiências, permitindo o acesso a lógicas sociais e culturais dos sujeitos subalternos. Palavras-chave: Eliane Brum. Micro-história. Jornalismo.

\begin{abstract}
This article takes part of a doctoral investigation in process. Aims to promote the dialogue between the microhistorical methodology and the journalistic practice of Eliane Brum, in the story A mulher que alimentava, published in the book $O$ olho da rua, which is analyzed. By adopting an epistemological path from the margins, it is noted that events take a social and cultural dimension, contrasted with the values legitimized by the dominant social history. Microhistory thus turns to problematic understanding of the particular. In this sense, the objective is to understand how the individual detail points to fragments of experiences, allowing access to the social and cultural logics of subaltern subjects. Keywords: Eliane Brum. Microhistory. Journalism.
\end{abstract}

Resumen: Este texto es resultado de una investigación doctoral en proceso. Promueve el diálogo entre la metodología microhistórica y la práctica periodística de Eliane Brum, teniendo el reportaje A mulher que alimentava, que hace parte del libro O olho da rua, como catalisador del análisis. Al adoptar un recorrido epistemológico a partir de los márgenes, los acontecimientos adquieren una dimensión social y cultural contrapuesta a los valores legitimados por la historia social dominante. La microhistoria se vuelve asi hacia la comprehensión problemática del particular. En este sentido, el objetivo es comprehender cómo el detalle individual apunta hacia los fragmentos de experiencias permitiendo el acceso a las lógicas sociales y culturales de los sujetos subalternos.

Palabras-clave: Eliane Brum. Microhistoria. Periodismo. 


\section{Introdução}

Ao relacionar a prática jornalística de Eliane Brum à metodologia micro-histórica procura-se compreender como se processa a objetivação dos chamados sujeitos "desimportantes" nas reportagens de O olho da rua. Para tanto, promove-se uma aproximação dos procedimentos utilizados pela micro-história com as práticas adotadas por Eliane Brum para a investigação, apuração e escuta das personagens.

Levi (2015) salienta que os documentos sintetizam realidades "parciais" e "mentirosas". Os arquivos para o historiador italiano, emergem em situações de decisão e ação - relegando para segundo plano noções mais subjetivas, como as hesitações, os sentimentos, as emoções e as esperanças.

Para autor de $A$ herança imaterial "os documentos são socialmente determinados, os ricos produzem mais documentos que os pobres, os homens mais que as mulheres, os brancos mais que os indígenas" (LEVI, 2015, p. 249). Nesse sentido, o problema que se apresenta aos historiadores é o de estabelecer o equilibrio, colocando todos como participantes da história.

Os documentos são necessários, mas são inimigos. O problema fundamental da micro-história, nesse sentido, é dizer que qualquer fragmento pode sugerir coisas se o olharmos com o microscópio. Isso permite reequilibrar, trazer à luz o que não aparecia antes porque estava escondido por dentro dos fragmentos documentários falsos que temos (LEVI, 2015, p. 249).

Essa perspectiva pode ser observada no segundo capitulo do livro A herança Imaterial, em que Giovanni Levi reflete sobre as estratégias utilizadas por três famílias de colonos de Santena. Na obra, o autor faz uma seleção entre uma centena de outros casos possiveis, sem estabelecer um tratamento comparável, baseando sua metodologia na presença nos arquivos prosopográficos. Desse modo, Levi não buscou configurar modelos estatísticos gerais acerca dos três colonos, mas abstrair elementos qualitativos.

Ancorado sob essas premissas, o trabalho de Giovanni, Levi se abre para uma discussão mais ampla e problemática dos contextos sociais. A exemplaridade dos fatos ${ }^{3}$ históricos, nessa acepção, é pensada não simplesmente em termos estatísticos, mas busca abranger dinâmicas sociais e antropológicas.

O olhar dos historiadores volta-se para a relevância e para a complexidade dos processos não lineares e para a pequena escala. Com isso, a experiência dos atores sociais e a catálise dos fragmentos cotidianos ganha uma profusa carga de significado.

Essa perspectiva atende, portanto, ao esforço para escrever uma história do ponto de vista da camada subalterna. Revel (2015) explicita que o projeto pode ser concebido em termos muito distintos. Em primeiro lugar, com a finalidade de assimilar conjuntos e caracterizar comportamentos globais e médios. Sob outro prisma, a história nas margens pode designar uma tarefa cuja lógica e o significado assentam-se sob as bases da singularidade das experiências. Para o autor, a metodologia micro-histórica permite a compreensão de que as vidas "minúsculas" também participam da chamada história "grande" conferindo uma versão diferente e complexa para a realidade social. Para Revel (2015), o problema não consiste tanto em contrapor um "de cima" a um "de baixo", o grande ao pequeno; mas em reconhecer que uma realidade social não é a mesma segundo o referencial de análise selecionado.

Lima (2006), ancorado no pensamento de Levi e Ginzburg, sustenta que o caráter generativo e processual da micro-história deve abarcar os parâmetros internos dos contornos da realidade individual e de suas variações - sem, no entanto, delimitá-las em formas finais abstratas, mas, mantendo as premissas de seu significado

\footnotetext{
3 Para os termos do presente estudo, a contextualização de fato e acontecimento são tomadas a partir do pensamento de Mique Rodrigo Alsina (2009). Para o autor, acontecimento é um fenômeno social e está determinado histórica e culturalmente. É claro que. cada sistema cultural vai identificar quais são os fenômenos que merecem ser considerados como acontecimentos e quais passam despercebidos. Os acontecimentos constituem um conjunto de fatos conhecidos. O fato constitui uma configuração concreta particular do acontecimento. Desse modo, os fatos seriam tudo que acontece no mundo. A notícia - para Alsina - se afirma como uma representação social da realidade cotidiana, gerada institucionalmente e que se manifesta na construção de um mundo possivel.
} 
individual. Nessa acepção, Lima (2006) traz à baila a opção pela escala reduzida de observação.

Na mesma senda, Ginzburg e Poni (1991) afirmam que o nome desempenha função essencial na configuração política, econômica e histórica da singularidade de um indivíduo. No percurso de desvendamento de realidades e contextos, os autores pontuam que o arquivo da grande propriedade - configurava-se como uma fonte pródiga para selecionar nomes de camponeses e lugares, além de permitir o acesso a outros arquivos, como registros paroquiais e cadastros, por exemplo.

A partir do apanhado dos fragmentos nominais é possivel reconstruir a trajetória de familias e individuos. Ginzburg e Poni (1991) ressaltam que o fio condutor desses trajetos "é, mais uma vez, o nome" (GINZBURG; PONI, 1991, p. 175). Os autores prosseguem:

Como já foi indicado, este jogo de vaivém não fecha necessariamente a porta à indagação serial. Serve-se dela. Uma série, sobretudo, se não manipulada, é sempre um bem utilizável. Mas o centro de gravidade do tipo de investigação micronominal que aqui propomos encontra-se noutra parte. As linhas que convergem para o nome e que dele partem, compondo uma espécie de teia de malha fina, dão ao observador a imagem gráfica do tecido social em que o indivíduo está inserido (GINZBURG; PONI, 1991, p. 175).

Para Ginzburg e Poni (1991), a reconstituição do nome desempenha o papel de diferenciação entre individuos, trazendo para o primeiro plano as particularidades e as pequenas narrativas. De modo semelhante, observa-se que no relato de Eliane Brum o nome singulariza histórias, problematiza contextos e complexifica realidades. Nesse sentido, a pergunta sobre o sujeito reconstitui as estruturas sociais. Os autores definem a microhistória como uma "prosopografia a partir de baixo", isto é, apresentam-na como uma busca para reconstituir uma biografia coletiva, tentando colocar em primeiro plano as ações e pontos de vistas das chamadas classes subalternas.
O procedimento é observado na reportagem "A mulher que alimentava" - que será analisada com mais detalhes no presente artigo. Na matéria, Brum narra os últimos quatro meses de vida da merendeira Ailce de Oliveira Souza, que tem um câncer em estágio terminal.

A reportagem está centrada na vida de uma pessoa comum - relatando seus fragmentos, falhas e temores diante de uma doença irreversivel. Desse modo, Brum consegue refletir sobre como as doenças terminais afetam a rotina dos indivíduos e de suas familias, traz para discussão a importância dos cuidados paliativos, pondera de modo tangencial sobre o sistema público de saúde e, principalmente, reflete sobre o sentido da vida, não a vida dos reis, presidentes, princesas e heróis, mas a vida que acontece nas minúcias e nos retalhos - como a vida singular de Ailce.

A partir do tensionamento desses elementos, Brum consegue trazer para o plano de observação as singularidades centradas no nome da merendeira Ailce, como também os dados de sua vida e os aspectos problemáticos que a condicionam além de estabelecer um diálogo profundo com as dinâmicas sociais, culturais e dos sentidos que atravessam a existência da merendeira.

A "corrente" italiana promove, como já se pontuou, uma mirada com o microscópio sobre o trivial, como forma de compreender a polissemia de sentidos e de representações narrativas que povoam os espaços histórico-sociais. Desse modo, as questões relativas ao cotidiano e ao indivíduo emergem como instâncias significativas do relato político, econômico, histórico e cultural.

As reportagens observadas em O olho da rua possibilitam a inteligibilidade das nuances, do aparentemente imperceptivel, do comum e do subalterno na configuração da realidade social. Desse modo, as paisagens sociais subalternizadas podem emergir como zonas de sentido e significação. Tal assertiva guarda uma atenta relação com a vida cotidiana, com os sujeitos comuns e com a subversão dos fatos. Isso implica um olhar insurrecto, um olhar insubordinado - contíguo à perspectiva jornalistica adotada por Eliane Brum. 


\section{Fontes e "Livro de repórter" em Eliane Brum}

Tendo-se em mente a complexidade de uma aproximação entre micro-história e jornalismo, faz-se necessário compreender como a prática de Eliane Brum subverte o modus operandi do periodismo tradicional e rearticula novos sentidos, novas gramáticas e semânticas acerca dos contextos histórico-sociais, culturais e também sobre o lugar dos anônimos na reportagem.

Brum foge ao caráter funcionalista atribuido às fontes noticiosas ${ }^{4}$ - tomando-as a contrapelo do tom homogeneizador. Coloca-se, nesse sentido, contrária às bases do jornalismo hegemônico, apresentadas por Borrat (2006), cujo regime de práticas e os procedimentos regulares instituem uma realidade sem nervuras - lisa, compacta e homogênea - apartada da complexidade das dinâmicas sociais, como por exemplo, das realidades subalternas. Por consequência, a aparição do sujeito comum na narrativa jornalística ocorre por meio de uma subordinação ritualizada ou ainda como estereótipo do poder social dominante, resultando em uma escala que não enxerga as minúcias, os vestígios e as rugosidades sociais.

O conceito de fonte liga-se ao pressuposto de origem, inicio, começo, surgimento, força geradora, causa primeira. Grosso modo, para Borrat (2006), qualquer ator social "pode ser fuente cuando desempeña ese rol respecto de otro actor comunicándole datos, significados, versiones del caso noticiable" (BORRAT, 2006, p. 246).

Para os termos do presente debate, percebese que além de apresentar dados, sentidos e uma "tradução" dos contextos sociais, as fontes engendram estruturas simbólicas de poder na sociedade - pois, corriqueiramente, os acontecimentos são estruturados sob o vértice das ideologias dominantes - solapando o alarido de vozes dos sujeitos comuns, relegando-os ao segundo plano.

Em conformidade com Borrat (2006), pode-se afirmar que a racionalização da profissão jornalística ratifica o postulado da técnica, das capacidades de interpretação e investigação e de uma escrita normatizada, "objetiva", "imparcial" e "neutra". Nesse sentido, a estrutura, as características textuais e a separação entre informação e opinião aparecem como elementos definidores do moderno jornalismo. Contudo, observa-se que o relato de Brum está inserido dentro do que Marocco (2016) define como "livro de repórter".

O "livro de repórter" promove uma mudança epistemológica nas bases da produção discursiva do jornalismo. Os saberes, as práticas e as experiências cognitivas deslocam-se em uma perspectiva jornalismo-jornalismo, tendo-se como foco a reflexão crítica da prática e a "formulação de uma figura autoral" (MAROCCO, 2016, p. 154).

Zamin (2011) explica que sob a designação "livro de repórter" podem ser observadas narrativas que se dedicam "de uma hermenêutica do jornalismo, seja pela crítica ou pela interpretação, para além de ofertar simplesmente uma grande reportagem" (ZAMIN, 2011, p. 394).

Os relatos empreendidos por Eliane Brum em 0 olho da rua promovem o deslocamento dos saberes legitimados pelos critérios de "objetividade" e "imparcialidade", ao se contrapor a uma visão hegemônica de explicação do mundo. Nessa direção, é possível encontrar no relato jornalístico zonas de resistência articuladas sob os vértices da crítica da prática, da autoralidade e do "livro de repórter".

Zamin (2016) explicita que Marocco examina o jornalismo pelo viés da crítica das práticas jornalísticas. Suas escolhas metodológicas não estão direcionadas à investigação da mídia pela própria mídia (ombudsman), ao estudo de

\footnotetext{
4 Na acepção de Gans (1979), a fonte pode ser compreendida como qualquer pessoa ou instituição que presta informações - na condição de membro ou representante de grupos organizados ou de diferentes segmentos da sociedade - para um jornalista. Gobbi e Kondlatsch (2017) citam McNair (1998) para apresentar uma taxinomia das fontes. Conforme o autor britânico, a classificação abrange distintos tipos de fontes, como de natureza (pessoais ou documentais, públicas ou privadas); duração (fontes episódicas ou permanentes): o âmbito geográfico (locais, nacionais ou internacionais); grau de envolvimento no fato (oculares/primárias ou indiretas/secundárias); atitude face ao jornalista (fontes ativas/espontâneas ou passivas/ abertas, resistentes); estatuto de visibilidade exigido (fontes assumidas ou fontes confidenciais); metodologia ou estratégia de atuação (fontes proativas ou reativas, preventivas ou defensivas) (GOBBl; KONDLATSCH, 2017, p. 38). No decorrer do tópico 3.3 serão discutidos de forma mais aprofundada o caráter hegemônico de algumas fontes e de que forma isso se traduz na configuração de uma realidade específica engendrada pelos media.
} 
crítica literária (tendo jornais e revistas como suporte analítico) ou "à crítica de outros campos teóricos sobre o jornalismo" (ZAMIN, 2016, p. 11). Marocco problematiza as hierarquias de controle discursivo do jornalismo (fatores endógenos e exógenos), marcados pela conjunção da tríade jornalistas, relações de subordinação e estratégias técnico-profissionais. No entanto, conforme aponta Zamin (2016):

[...] a autora [Marocco] não se dedica a buscar por aquilo que é adequado a um modo de objetivação jornalística, mas a compreender os tensionamentos próprios ao sistema de produção jornalística e as formas de resistência que são gestadas em meio a eles (ZAMIN, 2016, p. 12).

A metodologia empregada por Marocco (2016) espraia-se pela escuta cuidadosa do discurso dos jornalistas. Para alcançar seu objetivo, a autora recorre à utilização das entrevistas. Esse caminho possibilita a definição de comportamentos regulares, regras e procedimentos de controle. 0 entendimento de uma redação jornalística como locus de acomodação e resistência, comporta portanto, condutas, condições de produção e o emolduramento de um regime de verdade. Para Zamin (2016), a reflexão articulada por meio das entrevistas, processa uma epistemologia da prática:

\begin{abstract}
O jornalismo, aqui, é pensado pelos sujeitos que o exercitam, que dele fazem lugar para a recolha do tempo presente. Os e as jornalistas falam de si, e a escuta atenta da pesquisadora [Marocco] permite acessar o jornalismo para além das redações, dos manuais e de ferramentas que comumente são acionadas ao tentar explicá-lo (ZAMIN, 2016, p. 11).
\end{abstract}

O "livro de repórter" desempenha, desse modo, a articulação entre regras, práticas e técnicas jornalisticas, correlacionando-as a uma reflexão heuristica do fazer. O conceito não é hermético, mas se apresenta como apreensão do relato cotidiano, abarcando "a crítica das práticas jornalisticas articulada à experiência do jornalista e a subversão do estatuto de fonte" (ZAMIN, 2016, p. 12).
Em seu livro, Marocco (2016) discute as ações de resistência por meio das entrevistas realizadas com 17 jornalistas, entre eles Eliane Brum, Alexandra Lucas Coelho e Caco Barcellos, por exemplo. No âmbito do presente estudo, o campo de observação ficará restrito à análise da obra $O$ olho da rua, de Eliane Brum.

Para Silva (2018), o exame minucioso da prática discursiva da autora de $O$ olho da rua define um locus enunciativo para o sujeito e para a sua trajetória, influenciando "nas ações de resistência e subversão aos modos de objetivação jornalística que historicamente interdita a subjetividade e vem transformando diferenças em desigualdade" (SILVA, 2018, p. 2).

A redação se constitui como uma seara de embate e racionalidade do mundo. O estudo da prática dos repórteres permite problematizar as zonas de compreensão dos aspectos sociais, culturais e históricos para além da organização burocrática dos media, dos valores e das etapas de produção jornalística (apuração, técnicas de redação e convenções normativas) - comungando aspectos, como temporalidade, temas, choquese acontecimentos para a tessitura da escuta delicada empreendida pelo jornalista.

Observa-se, contudo, que mesmo cingidos por injunções do ethos jornalístico, repórteres como Eliane Brum articulam suas histórias de vida e trajetórias em contraposição aos valores institucionalmente privilegiados. Silva (2018) observa que - nestes casos - a prática jornalistica é sulcada por movimentos de resistência:

Ainda que os sistemas de valores e relações de poder hegemônicos predominassem nas interações observadas nas pesquisas e se refletissem nos discursos e nas práticas jornalisticas, pude perceber que alguns profissionais conseguiam não apenas refletir sobre suas práticas, mas sobretudo que essas práticas se diferenciavam no modo como a realidade era observada e descrita, abrindo margem para um melhor encontro de alteridades também nas narrativas sobre o Outro (SILVA, 2018, p. 5).

Em Eliane Brum, verifica-se que o exercicio da atividade jornalística fia-se pelo esboroamento de 
complexos códigos de semantização do mundo. Delineia-se, nessa ordem, uma intricada rede de discursos, marcada por distintos sujeitos sociais e lógicas de cognição que, em conjunto, traduzem "as histórias de vida de alguns profissionais" como "parte de seus discursos" (SILVA, 2018, p. 6).

Nessa direção, observa-se que a apreensão do mundo - para Brum (2014) - é filtrada por uma lupa familiar. Sua primeira experiência narrativa se deu com o túmulo da irmã. A infância foi assinalada por visitas reiteradas, juntamente com os irmãos, à sepultura da "Maninha". Essa imagem marca profundamente a memória da autora de O olho da rua, precisamente, porque, para Brum, a morte cala o mundo das palavras:

Desde o início o mundo doeu em mim. Dentro, mas também fora. Alguns creem que as memórias da primeira infância ou são boas ou não existem, temerosos de que até o mito da infância feliz lhes escape. São os que preferem não lembrar. Eu lembro muito, sempre lembrei. E ainda hoje há noites, muitas noites, em que acordo com o coração descompassado. Sempre vou temer o retorno da escuridão, que para mim é o mundo sem palavras (BRUM, 2014, p. 12).

Outro túmulo particular é o de Luzia de Figueiredo Neves - a professora que ensinou as primeiras letras a Argemiro Jacob Brum - o pai de Eliane. A autora de $A$ vida que ninguém vê conta que a primeira descoberta de seu pai foi saberse Argemiro. Em casa e por todos era conhecido apenas como "Nenê". Brum relata que quando Luzia chamou por "Argemiro" na escola, seu pai, "então um guri de sete anos, não se mexeu. Só na terceira ou quarta chamada, reconheceu-se. E com o nome veio um mundo inteiro" (BRUM, 2014, p. 73).

Para contrapor ao túmulo de morte, eu tinha este, o de Luzia. Sobre a lápide da mulher que nos deu a luz, com e sem crase, produzi meu segundo nascimento. Escolhi minha linhagem, meu lugar simbólico de pertencimento. Com a memória de Luzia, fiz meu parto para a vida - e a vida era a palavra escrita (BRUM, 2014, p. 77).

As novelas de rádio também forneceram à Brum as chaves da escuta e da imaginação. Ao observar da porta da cozinha as lágrimas da empregada, a pequena Eliane tecia vaticínios sobre "o poder da história contada" (BRUM, 2014, p. 25) na vida da moça - que "soluçava por uma mulher que morava dentro do rádio" (BRUM 2014, p. 25).

O rosto fechado da empregada se abria enquanto escutava as (des)aventuras de personagens que, para ela, eram mais reais do que eu. Não posso dizer que compreendia o que se passava, mas entendia o suficiente para registrar que algo de extraordinário acontecia com as pessoas quando elas ouviam histórias. Acho que a empregada escutava a novela, e eu escutava a empregada. Naqueles minutos que duravam cada capítulo, aquela moça não apenas queria ser a heroina, mas se tornava a heroina (BRUM, 2014, p. 28).

A alquimia entre observação e escuta permitiu que Eliane Brum se tornasse "uma escutadeira que conta. E conta. Para contar" (BRUM, 2014, p. 33). A avó materna, Teresinha, também a inseriu no universo das histórias - reais e das que poderiam ter acontecido. Era corriqueiro Brum ficar perdida entre os bibelôs da avó, ouvindo os causos de Pedro Malasartes. "Eu pedia sempre e sempre que minha avó repetisse as histórias, só para vê-la gargalhar" (BRUM, 2014, p. 35).

\begin{abstract}
Mas o melhor da minha avó eram as histórias urdidas com retalhos pinçados do território sem fronteiras do ontem. Ela era cheia de contos, e eu tinha ouvidos gulosos. Desde pequena, sou capaz de permanecer horas só escutando, sem a necessidade de falar de mim mesma. Pelas fábulas de familia minha avó resgatava um pretérito que nunca teve. Se não era possivel alcançar um amanhecer mais próximo de seus suspiros, ela compensava alinhavando seu antes com linhas bem coloridas, às vezes extravagantes. Minha avó sabia que, para algumas vidas, é mais fácil mudar o passado que o futuro (BRUM, 2014, p. 36).
\end{abstract}

Brum (2012) recorda que seu tio tinha um armazém (bolicho), em ljuí, no interior do Rio Grande do Sul, em que se reuniam os membros da comunidade. No estabelecimento eram vendidas balas, salame e as pessoas se encontravam no local para jogar cartas e contar histórias. Desde pequena Brum adota uma característica que 
perpassa a sua prática jornalística - ela é mais "escutadeira" e "olhadeira" do que "faladeira". No bolicho do tio, começaram a ser aprimoradas as técnicas da jornalista: "E eu ficava ouvindo histórias. Então comecei a me tornar repórter lá" (BRUM, 2012, p. 72). Eliane Brum aprendeu a ler aos sete anos. A prática da leitura the permitiu apalpar o mundo, "viver outras aventuras e ser outros personagens. Desde então leio todos os dias" (BRUM, 2012, p. 72). Brum destaca que sempre teve predileção por histórias:

[...] meu pai é historiador e sempre teve
muita preocupação em contar a história
da comunidade. A história da nossa fa-
mília. A gente fazia as pequenas viagens
da familia, e ele sempre ia contando
histórias no caminho. Então, cresci nes-
se mundo de histórias reais. Mas nunca
pensei em ser jornalista, porque achava
jornal uma coisa muito chata. Por que eu
achava chato? Porque não encontrava
gente, não encontrava aquelas histórias
que gostava de ouvir. Era uma coisa
que naquela época era árida para mim
(BRUM, 2012, p. 72, grifo nosso).

Brum cursou História e Jornalismo simultaneamente, mas não chegou a se formar na primeira graduação. A autora de $A$ menina quebrada, inicialmente, não se via exercendo a atividade jornalistica. Primeiro, porque era tímida. Segundo - porque não gostava de jornal. Quem a fez mudar de ideia sobre o jornalismo foi o professor Marques Leonam - que lhe apresentou um estilo jornalístico mais aberto ao relato das histórias e às possibilidades da escrita.

Leonam foi professor de Eliane Brum na cadeira de estágio. Com ele, Brum fez a sua primeira grande reportagem - que era sobre as filas que o sujeito enfrenta desde que nasce até morrer. Com a reportagem, Brum concorreu a um estágio no jornal Zero Hora - vencendo-o.

A experiência entretecida pela narrativa familiar, pelas histórias ao pé do ouvido, pelo exercício regular da leitura e pelo olhar detido à escuta do outro forneceram à Brum os "instrumentos" iniciais para a sua "caixa de ferramentas". Por conta disso, o ouvir assume uma conotação metodológica de aproximação, de empatia e de espanto - na prática da jornalista gaúcha. O ouvir convertido em escuta atenta permitiu a Brum calar a voz da jornalista que apenas lança perguntas, para em seu lugar deixar nascer a repórter diligente aos detalhes, aos anônimos e às vidas comuns.

Em O olho da rua ficam manifestas as complexas redes de sentido articuladas pelo relato jornalístico de Eliane Brum. Para cada uma das dez reportagens que compõem o livro - Brum escreve um comentário apontando o processo de escrita, os aspectos problemáticos da narrativa e como determinada história foi urdida.

Essa ação descreve um duplo deslocamento da prática - primeiro, em direção a uma hermenêutica jornalística; e em segundo lugar para ratificar uma criação autoral. Para Marocco (2016), o que emerge como ponto fulcral neste momento é a compreensão da figura do jornalista e do saber materializado nos "livros de repórter", que apontam para

\begin{abstract}
a existência de um jornalista que critica a prática e, ao mesmo tempo, pode criar um modo de produção autoral nos livros que escreve. [...]. Por esse viés, poder-se-ia argumentar que estes livros ["livros de repórter"] se desviam do discurso vigente no jornalismo e, embora não deixem de fazer jornalismo, neste outro espaço, os jornalistas são agentes de um modo jornalístico de objetivação autônomo, que pode ser conjugado ao exercício da interpretação crítica no comentário (MAROCCO, 2016, p. 97).
\end{abstract}

O jornalismo é atravessado por um conjunto de regras, códigos e convenções - que, em conjunto, formulam-no como prática discursiva concreta. Por meio dessa lógica se estabelecem algumas paisagens modelares - centradas, por exemplo, na hegemonia de algumas fontes em detrimento de outras e na ideia de "objetividade", "imparcialidade" e "verdade". Em contraposição à ideologia positivista e liberal da indústria jornalística, Brum opta por uma aproximação como enfatiza Marocco (2016) - aos "individuos à margem da sociedade" (MAROCCO, 2016, p. 63).

Veloso e Pavan (2014) apontam que a prática jornalística de Eliane Brum direciona-se para o acolhimento empático do outro. Essa 
compreensão passa pela capacidade que a autora de $A$ vida que ninguém vê tem de identificar nos dramas dos entrevistados o deslinde de comportamentos, racionalidades e situações referentes à própria humanidade, como "um esforço diário de resistência" (VELOSO; PAVAN, 2014, p. 229).

Na prática jornalística, como na vida, ampliar a experiência do encontro com o outro, percebendo-o em suas distintas dimensões, implica a recusa ao medo de compreender a realidade dos personagens e dos caminhos a que suas histórias conduzem. Requer a capacidade de observar pessoas e fenômenos ao redor, posto que, mais do que olhar, é necessário aprender a perceber. É desse esforço que nasce a capacidade de notarmos "a beleza profundamente surpreendente e significativa das coisas cotidianas" (Vilas Boas, 2003, p. 29) (VELOSO; PAVAN, 2014, p. 229).

As reportagens de Brum presentes em O olho da rua são tecidas sob o prisma de um "olhar detido e compassivo" - fugindo às amarras totalizadoras do relato jornalístico. Em sua narrativa, as antinomias da vida das personagens emergem como um istmo - atando realidades, sujeitos e histórias - a estratos socioculturais mais amplos e profundos.

Veloso e Pavan (2014) constatam que a prática de Brum é marcada pelo afastamento à concepção de impessoalidade da narrativa jornalística e pela negação da demanda pelo fato sensacional. Sua prática define-se - por outro lado - como jornalismo de "desacontecimentos".

Para Ventura e Abib (2015), o jornalismo de "desacontecimentos" situa-se na contramão dos valores consagrados pela tribo jornalística, ao definir as reportagens como locus de "resistência ao modo de produção noticioso da grande mídia, cuja fundamentação encontra-se nas técnicas e valores jornalísticos aplicados por Eliane Brum [...] ao longo da carreira profissional" (VENTURA; ABIB, 2015, p. 137).

O percurso delineado pela prática jornalística de Brum também não se insere dentro da lógica do jornalismo literário. A repórter do El País afasta-se dos sintagmas definidos pela máxima do "jornalismo investigativo" ou do "jornalismo literário". Para a autora de $A$ vida que ninguém $v e \hat{e}$ o "jornalismo é tão substantivo que não precisa de adjetivo" (BRUM, 2012, p. 89). Nesse sentido, o jornalismo de "desacontecimentos" é caracterizado pela complexificação dos contextos sociais, culturais e históricos. Brum explica:

\begin{abstract}
Há bom jornalismo e mau jornalismo. O que é bom jornalismo? O bom jornalismo é aquele que compreende que a realidade é muito mais complexa do que aquilo que é dito. Infelizmente, boa parte dos repórteres se deixou reduzir a aplicadores de aspas em série. E a vida não é isso. Quando estás fazendo jornalismo assim, estás fazendo algo meio criminoso, que é o ato de reduzir a vida, reduzir a complexidade do real. Então, o bom jornalismo é aquele que escuta o dito e o não dito, escuta os silêncios, aquele que sabe que os gestos e os cheiros podem ser informações tão importantes quanto a palavra. O bom jornalismo trabalha com tudo que é da realidade e leva ao leitor o máximo de complexidade possivel, para que o leitor possa ir onde ele não foi e, a partir daí, faça as suas próprias escolhas (BRUM, 2012, p. 89).
\end{abstract}

Ao contrapor os elementos da prática jornalística convencional aos parâmetros de uma metodologia de "desacontecimentos", Eliane Brum deixa patente a escolha por um tipo particular de reportagem - cujo traçado passa pela inteligibilidade das complexas estruturas que atravessam o cotidiano das cidades brasileiras, das Amazônias, das periferias e também pelas possibilidades presentes na vida dos sujeitos anônimos, subalternos, esquecidos.

A narrativa de Brum é "construida" a partir das frestas do acontecimento - como sensibilidade sublimada das rotinas, como reconhecimento do outro e como hermenêutica do olhar. A jornalista gaúcha ilustra essa perspectiva com a história de Vanderlei - que ela conheceu quando escrevia a coluna "A vida que ninguém vê"5. O sujeito sintetizava o que é comumente conhecido como

5 A coluna "A vida que ninguém vê" é composta por 46 textos produzidos durante o ano de 1998 para o jornal Zero Hora. Por quase 11 meses Eliane Brum escreveu uma série de reportagens sobre personagens e cenas cotidianas no formato de crônicas da vida real. Em 1999, a coletânea venceu o Prêmio Esso de Jornalismo - Regional Sul. No ano de 2006, a obra A vida que ninguém vê foi publicada em formato de livro. 
um "personagem folclórico".

O homem todo ano aparecia na maior feira agropecuária do Rio Grande do Sul, montado em um cabo de vassoura - que era seu cavalo. O "alazão" passava pela inspeção veterinária e realizava todos os exames necessários. Vanderlei era conhecido como o "louquinho da Expointer":

Um dia, emparelhei meu cavalo com o dele. Perguntei: "Vanderlei, você é louco?". E começamos a conversar. A certa altura ele disse: "Você acha que eu não sei que meu cavalo é um cabo de vassoura? Mas pensa, raciocina (e batia a mão fechada na cabeça). Eu nunca vou ter um cavalo de verdade. Você não acha melhor eu acreditar que o cabo de vassoura é um cavalo?". Só me restou o silêncio. Se ele era louco, eu era o quê?

Vanderlei desejava tanto um cavalo que deu patas, crinas, carne, ossos e sangue a um cabo de vassoura. Reinventou sua vida da maneira que lhe foi possivel. Com a infinita liberdade conquistada, para Vanderlei tanto fazia se era um cavalo ou um cabo de vassoura. Tornara-se capaz de entregar-se ao galope desenfreado de um pampa imaginário. Afinal, quem diz o que é um cavalo ou o que é um cabo de vassoura? (BRUM, 2013, p. 55-56).

Percebe-se, desse modo, que a prática de Brum distancia-se daquilo que Traquina (2013) define como tribo. Para o autor, os jornalistas compartilham um conjunto de crenças cognitivas, perceptivas, avaliativas e referenciais sobre a realidade - ratificando o postulado de costumes e normas entre os membros do grupo.

Traquina (2013) referencia McManus (1994), Breed (1955), Epstein (1973), Tuchman (1978) e Hall et al. (1978) para explicar que o processo de produção da notícia é atravessado por um compósito de forças - representadas, pela figura do mercado, pelas injunções organizacionais, pelas rotinas e pelo acesso ao campo jornalístico.

O autor português salienta que as notícias são engendradas por profissionais que dividem uma "forma de ver" comum. A partilha de uma cultura noticiosa análoga - articula o pressuposto de que "os jornalistas são uma comunidade ou tribo interpretativa transnacional, e que a cobertura noticiosa em paises diferentes revela semelhanças significativas" (TRAQUINA, 2013, p. 28).

Ao reportar às discussões propostas por Traquina (2013), Ventura e Abib (2015) observam que a "tribo jornalistica" é entrecortada por traços de uma episteme profissional, técnica e cultural do fazer jornalístico. Disso redunda que a "tribo" desvela uma forma especifica de ver, falar e se manifestar - ao obliterar diferenças, privilegiar saberes de reconhecimento e pelo fato de sua narrativa adotar uma postura condescendente com as fórmulas homogêneas de "tradução" da realidade - marcada por uma apologia à simplificação das complexidades histórico-sócio-culturais.

Para Silva (2018), o estudo da prática de Brum possibilita a abertura para um novo modelo noticioso ao promover o descentramento de valores arraigados no paradigma jornalístico:

Há também o interesse em perceber
como o conjunto de saberes culturais e
institucionais foi sendo (re)elaborado a
partir de suas posições de sujeito e per-
cursos pessoais, criando brechas para
um fazer jornalistico menos reprodutor
dos sistemas de valores dominantes.
Penso que possa-se encontrar caminhos
para a elaboração de práticas pedagó-
gicas que contribuam para que o jorna-
lismo possa, mais amplamente, cumprir
sua função social. Função esta que vem
sendo dificultada especialmente pela
predominância de narrativas que tem
servido para reproduzir e reafirmar os
valores dominantes e excludentes, (re)
produzindo estereótipos e estigmas a
grupos historicamente vulnerabilizados
em nossa sociedade (SILVA, 2018, p. 6).

A trajetória profissional de Eliane Brum é marcada - como referencia Silva (2018), por uma hermenêutica da prática, pela escuta, pela alteridade e pelo "trato com a diferença" (SILVA, 2018, p. 6). Nas entrevistas, colunas, reportagens e depoimentos da autora de $A$ menina quebrada emergem fissuras - cujo preenchimento se apresenta pela emergência de novos sujeitos sociais, realidades e pelo fracionamento de concepções estandardizadas acerca dos espaços culturais e históricos.

A prática despe-se de suas convenções, padrões e cânones sacralizados - equilibrando-se nas bordas dos saberes hegemônicos. É a partir 
das fímbrias da narrativa jornalística que Eliane exercita sua escuta de espera e elabora o seu jornalismo de desacontecimentos.

\section{"A gente vai despida para o mundo do outro": 115 dias com Ailce}

Na reportagem "A mulher que alimentava", Eliane Brum acompanha os últimos 115 dias da vida da merendeira Ailce de Oliveira Souza. No periodo de 2008 a 2010, quando era repórter especial da revista Época, Brum abordou a morte como tema de suas matérias. A primeira - com Ailce, foi publicada em agosto de 2008. A última reportagem, intitulada "O filho possivel"6, foi divulgada em abril de 2010.

A vida familiar de Eliane Brum, como já foi pontuado, é marcada pelo pesar da morte precoce da irmã, terceira filha de seus pais, que morreu aos cinco meses. As vozes de "Maninha" e de Luzia emergem nos relatos de Brum como afeição compreensiva, como empatia, como possibilidade para a escuta. Ancorando-se, aqui, sob as bases da micro-história, é possivel ponderar que as reminiscências do luto familiar por que passa Eliane Brum ajudam na construção da narrativa sobre o outro - justamente, porque ampliam o debate sobre a pequena indicação como postulado científico, permitem uma definição especifica sobre o contexto e promovem uma racionalização dos processos histórico-sociais.

A elaboração do luto familiar possibilita a Brum observar a dor do outro por meio de uma cumplicidade que escuta e acalanta - distanciandose, portanto, da máxima da prática jornalística que prega uma denegação da subjetividade. Para Silva (2018), o postulado da subjetividade é apagado dos espaços de linguagem e das zonas de reflexão crítica sobre a prática jornalística. Em seu lugar são adotadas máximas consagradas pela impessoalidade, pela neutralidade e pela ideia de verdade

Ao conjurar a subjetividade com um olhar heurístico, Brum alcança as sutilezas que circunscrevem as vidas comuns, alçando-as ao âmbito da reflexão, da problemática e da significação. O pensamento sobre a morte da irmã permite a Brum traçar uma narrativa de proximidade, compreensiva e terna para si e acerca da vida do outro. Movimento semelhante pode ser observado quando Brum narra as minúcias e os detalhes da vida de Ailce. O deslocamento, como se constata, é empático. A percepção sob os domínios da vida do outro é atravessada pela compreensão do luto familiar.

Na constituição dos sujeitos promovida pelo relato de Brum, as correspondências entre passado/presente podem ser observadas por meio da sequência das experiências individuais narradas - que abrigam em seu bojo os ritos cotidianos e as catálises, isto é, todos os processos, contextos e eventos negligenciados quando se leva em consideração a tessitura da prática jornalística.

Nesse sentido, a memória da Brum criança visita a Brum adulta, entretecendo nos tênues fios que ligam passado e presente, uma fórmula crítico-edulcorada para lidar com a dor e com a morte - que não se encerra no caráter objetivo da narrativa de uma vida, mas que é clivada por paisagens interiores, texturas e subjetividades.

Para a autora de $A$ vida que ninguém vê, a escrita sobre o luto constitui uma forma de compreensão da perda e uma maneira de tornar possivel o seguir adiante. Percebe-se nas reportagens de teor elegíaco, o olhar acariciador e a escuta diligente de Eliane Brum - que opta por uma olhadela obliqua, de canto, das margens. Ao focalizar a morte em suas narrativas, Brum busca transformar a dor em relato de vida por meio da elaboração da ausência:

De certo modo, é o que tento fazer aqui. Escrevo para transformar. E sou transformada pelo que escrevo. Pego meu luto por tantos desencontros e o transformo em história contada, na esperança de dar a contribuição que me é possivel para o início de uma mudança no nosso olhar sobre a morte. E sobre a vida (BRUM, 2013, p. 99).

\footnotetext{
- Na reportagem, Eliane Brum acompanha a Divisão de Neonatologia do Centro de Atenção Integral à Saúde da Mulher (Caism), da Universidade de Campinas (Unicamp). Na Divisão são oferecidos cuidados paliativos no tratamento de bebês malformados ou com doenças graves. "Todos os esforços são empreendidos para curar. Quando não é possivel, a equipe suspende tratamentos invasivos e dolorosos - e amplia os cuidados com a família e com o luto. Cada bebê tem uma história. E é preciso cuidar bem dela" (BRUM, [2010]).
} 
Ao subverter as bases do paradigma jornalístico e instaurar uma postura de desvio em relação aos relatos hegemônicos, Brum deixa patente o seu caminho em direção ao outro. Para a composição da narrativa sobre Ailce, por exemplo, a reportagem distancia-se do tom sensacionalista comumente atrelado aos acontecimentos que abordam o luto, a morte, o câncer - e opta por narrar o intricado de uma vida.

Na reportagem "A mulher que alimentava", Eliane Brum articula um conjunto de elementos observáveis na micro-história italiana, como o método nominativo, o paradigma indiciário, a escala de observação e a instância narrativa. No exemplo apresentado a seguir, ficam evidenciadas características marcadas pela escuta atenta, pela diligência aos pormenores e pelo aprofundamento dos aspectos histórico-sócio-culturais da personagem Ailce.

"É tão estranho", ela diz. "Eu passei a vida inteira batendo ponto, com horário pra tudo. Quando me aposentei, arranquei o relógio do pulso e joguei fora. Finalmente eu seria livre. Ai apareceu essa doença. Quando tive tempo, descobri que meu tempo tinha acabado."

Ela está intrigada com essa traição da vida. Quando fala, sua expressão é de perplexidade. Ailce de Oliveira Souza não é uma filósofa, é uma merendeira de escola. Toda a sua vida havia sido de uma concretude às vezes brutal. Toda a sua vida havia sido uma sequência de atos. E agora a morte chegava exigindo metáforas.

[...]

Ailce nunca deixou de se sentir traida por "essa doença", como se expressa na maior parte das vezes, ou "o tumor". Não pronuncia a palavra câncer. Quando nos conhecemos, em 26 de março, fazia quase um ano que sua pele amarelara e ela se enchera de náuseas. Ela atravessa um período de grande revolta contra Deus. É difícil compreender a morte, a tragédia, o mosquito da dengue, o câncer.

O câncer de Ailce é uma pedra no meio do caminho das vias biliares. $O$ tumor obstrui a passagem e, sem ter por onde escoar, a bile é lançada no sangue e a amarela inteira. Quando ganha essa cor solar, Ailce ainda não tem 66 anos. E acredita viver o melhor tempo de sua vida. "Sem filhos, sem marido, sem compromissos, aposentada, livre", resu- me. Ela planeja conhecer as obras de Aleijadinho, nas cidades históricas de Minas Gerais, e a Espanha dos filmes de Sarita Montiel. Descobre que quando viaja esquece de tudo. E, quando a paisagem passa veloz pela janela do ônibus, sente que está indo para onde sempre quis, não importa o destino. "Você já reparou como a gente muda quando viaja?" (BRUM, 2008, p. 383-384).

Ao apresentar a merendeira Ailce de Oliveira Souza, a autora de O olho da rua não se detém ao relato da doença. O câncer perpassa toda a narrativa como uma elipse - não está na voz da jornalista Brum e, tampouco, no desenho dos dias de Ailce. O que a repórter deseja é juntar os fragmentos dessa vida e encontrar o seu sentido. Para alcançar esse objetivo - Brum comenta que é necessário se despir para o mundo do outro, compreender a realidade que se apresenta e ser preenchida por ela.

Desse modo, constata-se que ao se debruçar sobre o relato da história de Ailce, Brum empreende um caminho pelos sentidos da doença e pela arquitetura da biografia da merendeira - não as tratando como antinomias frias, mas buscando aprimorar o olhar sobre a sociedade e sobre a existência de Ailce. O enfoque direciona-se, portanto, para a compreensão problemática da vida da merendeira.

O movimento empreendido por Brum aproximase dos pressupostos metodológicos assinalados por Ginzburg (2007), compreendendo um processo de coleta, interpretação e narração. Nessa senda, a adoção de uma escala reduzida - tomando-se a personagem Ailce como "modelo" de estudo - privilegia os detalhes, os acontecimentos e as conexões, com o fito de compreender como se articulam as textualidades, materialidades e as circularidades de sentidos oriundas das margens e da complexidade do cotidiano.

Ao compor com as lacunas - a autora de 0 olho da rua traz para o plano da reportagem as incertezas e as hipóteses - articulando-as em um relato coerente. Desse modo, Brum consegue transpor para o plano da reportagem as assimetrias da realidade social, percebendo-a como descontínua e heterogênea. A esse respeito, 
aludindo ao pensamento de Santos (2014), verifica-se que "a partir do olhar aproximado, podemos capturar algo que pode nos escapar na visão de conjunto" (SANTOS, 2014, p. 6).

Além das metodologias já elencadas, a autora de O olho da rua relaciona distintas escalas vagueando entre o macro e o micro. Nessa acepção é que comportamentos, sonhos e acontecimentos da vida de Ailce emergem da tessitura da narrativa como fios que vão cosendo fragmentos a outros pontos esparsos - até montar, dentro do possivel - o desenho da vida da merendeira e de seu sentido existencial.

A narrativa em desacontecimentos de Brum direciona-se para a compreensão dos desejos, alegrias e inquietações de Ailce. A existência da personagem é traduzida como luta e transgressão. A reportagem "A mulher que alimentava" abarca, portanto, o sentido mais amplo das dores humanas - sem se deter, unicamente, na morte, mas adentrando as profundezas do território da vida - com seus interditos, suas faltas, seus silêncios, alegrias e sutilezas.

Para Brum, toda história narrada é um corpo que pode existir, "é uma apropriação de si pela letra-marca de sua passagem pelo mundo. 0 ponto-final de quem conta nunca é fim, apenas princípio" (BRUM, 2014, p. 111). Constata-se, aqui, o deslocamento que Brum empreende em direção ao outro. A retórica das aspas cede lugar à semântica dos indícios, lacunas e não ditos do entrevistado. A escuta ponderada emerge como ferramenta da prática de Eliane Brum:

Escutar é tu não interromper quando a pessoa está falando [...]. Escutar é estar aberto para o espanto, é estar aberto para se surpreender. É tu te despir. Eu acho que cada reportagem, cada entrevista te exige isso: é tu te despir daquilo que tué, dos teus preconceitos, da tua visão de mundo e chegar o mais vazia para aquele momento e conseguir realmente escutar com todos os sentidos o que aquela pessoa está dizendo. Então, eu tenho todo o tempo do mundo, sempre, mesmo que depois tenha que virar a noite escrevendo, se for o caso. Eu escuto com todo o tempo que for. porque cada pessoa também tem o seu tempo de falar (BRUM, 2011, p. 310).
A prática de Eliane Brum descreve dois movimentos: um de "esvaziamento" e outro de escuta. No caso específico de Ailce, o "vazio" a que Brum se refere alude à ideia de preenchimento pela história do outro, pelos seus desvios, incompletudes, desatinos e acertos. Nesse sentido, para relatar a história da merendeira, a jornalista necessita desembainhar suas visões de mundo e preconceitos - para compor uma reportagem com os indícios, com os fragmentose com os vestígios contidos na vida da personagem.

O processo de esvaziamento e escuta presentes na prática de Eliane Brum partem de uma complexa apreensão dos indícios e dos vestígios. O paradigma indiciário proposto por Carlo Ginzburg (2007) investiga os fatos sociais sob o prisma do detalhe e do aparentemente supérfluo. O método distingue-se por apresentar um caráter interdisciplinar, destacando-se pela análise criativa dos documentos, dos contextos e dos sujeitos sócio-históricos.

Zorzal (2014) destaca que a microanálise proposta por Ginzburg se baseia na redução da escala de observação do ponto de vista do pesquisador. O objetivo não é transformar os elementos individuais em conhecimento generalizado, mas salientar as particularidades:

Ao desenvolver o método indiciário, Ginzburg tomou como base os estudos realizados pelo médico e especialista em arte Giovani Morelli. O objetivo de Morelli era identificar falsificações de pinturas famosas. Para isso, desenvolveu um estudo muito peculiar sobre os pormenores que costumavam ser até mesmo negligenciados, tais como lóbulos de orelhas, unhas das mãos e dos pés e formato dos dedos, por exemplo. Coelho (2014) explica que esses pormenores tomavam nova dimensão, sendo reveladores enquanto indícios e pistas. Assim, seu método partia de dados que eram considerados marginais, secundários (ZORZAL, 2014, p. 78).

Zorzal (2014) salienta que o paradigma indiciário apresenta dois pontos de encontro com o jornalismo. O primeiro relacionado à rotina profissional. O segundo diz respeito à compreensão da pesquisa em comunicação sob 
o ponto de vista dos sinais, indícios e pistas. As reportagens presentes em O olho da rua situam-se sob as fimbrias de realidades evanescidas - que, graças ao olhar perscrutador da repórter Eliane Brum conseguem reconstruir os acontecimentos jornalisticos de forma problemática sob as bases de uma realidade subalterna e "sintomática".

Desse modo, observa-se que o trabalho de Brum não privilegia a identificação com sistemas simbólicos gerais ou universais do ethos jornalístico - mas antes, busca entender o que acontece no processo inacabado de um relato e de uma história. Revel (2015) enfatiza no preâmbulo de Juegos de escalas que a complexidade e o caráter intensivo do procedimento microanalítico têm como mérito principal:

[...] ajudar-nos a entender melhor a rede de lógicas sociais, também resistir melhor à tentação de uma reificação de ações e relacionamentos, bem como às categorias que nos permitem pensar sobre elas (REVEL, 2015, p. 16). ${ }^{7}$

Apesar do que possa insinuar o termo "esvaziamento" - a repórter não recorre à tessitura da vida de Ailce sem conhecê-la, examiná-la e entendê-la; trata-se, aqui, pelo contrário, de uma aproximação afetiva, compreensiva e complexa ao mundo do outro. Esvaziar-se, grosso modo, é exercitar o olhar para o espanto. Brum (2011) ressalta que só é possivel se surpreender depois de se lançar ao mistério. Isso, por outro lado, exige uma abertura para o novo, para sublevar conhecimentos consolidados e para a compreensão da realidade do entrevistado:

Eu acho que a gente tem que ir aberta. É muito importante tu ir [sic] aberto. $\mathrm{O}$ anti-jornalismo é aquele cara que vai com a sua tese pronta e encaixota a realidade dentro da sua tese. Para isso não precisa ir para a rua. Isso é invenção. Isso, sim, é ficção. Tem que ir aberta para se espantar, para ouvir. O melhor é quando tu te espantas. Quando a tua pauta vira, quando o imprevisivel acontece e tu acolhes o imprevisto. Isso, para mim, é quando eu fico mais feliz. Eu tenho que saber muito para poder me espantar, não é? Senão, qualquer coisa vai me espantar. E não devia. Então, o bom é quando tudo vira. Eu vou muito aberta (BRUM, 2011, p. 319).

Ao ser preenchida pelos hiatos da vida narrada, Brum se abre para a descoberta, para a observação, para assimilar os sentidos da existência de Ailce. Nesse movimento, os espaços vazios, as incompreensões e as lacunas vão sendo povoados pelos detalhes, pelas texturas e pela escuta diligente. O ouvir, desse modo, aparece como uma atitude heuristica de revelação.

Isso pode ser constatado quando Eliane Brum é confrontada com as sutilezas da biografia de Ailce - principalmente, pela forma como a merendeira lida com a sua doença, pela maneira como compreende a ideia de liberdade e pelo modo como a luz interior vai se calando pouco a pouco dentro dela.

Os ritos de uma existência só podem ser percebidos com essa sutileza, quando o repórter alia atenção delicada a escuta dos interditos o que lhe permite alinhavar os acenos de uma vida na forma de um relato, de uma narrativa. Sobretudo, porque a prática de Brum interpela nos gestos sinais inaudiveis aos olhos nus de ternura. Pode-se observar essa perspectiva no excerto apresentado a seguir:

Ailce anda de ônibus por todo lado, dança em bailes da terceira idade, tem um romance com um homem mais jovem. "Me sinto leve quando eu danço, solta, solta, livre", diz. "Você acredita que quanto mais eu danço mais tenho vontade de dançar?" Ela prefere dançar sozinha pela liberdade de rodopiar pelo salão sem que ninguém a conduza. Sempre quis dirigir ela mesma a sua vida. Escolhe seus passos no salão de baile enquanto no interior do corpo que rodopia suas células a traem em silêncio.

Se câncer é a palavra que ela não diz, liberdade é a palavra que repete. De novo a concretude da vida de Ailce. Ela está presa, literalmente. Sua vida depende de duas mangueiras fincadas dentro dela. Elas drenam a bile para fora do seu corpo. E deságuam em dois recipientes de plástico que ela carrega numa sacola de supermercado

\footnotetext{
7 Do original: [...] el de ayudar-nos a comprender mejor el entramado de las lógicas sociales, resistir mejor también a la tentación de una reificación de las acciones y de las relaciones, asi com de las categorías que nos permiten pensarlas.
} 
nas andanças pela casa, numa bolsa decorada com as princesas da Disney quando passeia. Um dia um segurança de supermercado olha feio para sua bolsa de bile. Acha que ela está furtando coisas da prateleira. Com vergonha de carregar os líquidos do corpo numa sacola, devagar Ailce vai deixando de sair. Desliga a música dentro de casa. E não dança mais (BRUM, 2008, p. 386).

Ao se despojar de suas visões de mundo e ao ser absorvida pela realidade de Ailce, Brum estabelece um percurso de observação, análise e empatia. Para compreender a vida da merendeira é necessário mergulhar nas margens de seu mundo, experimentar de seus medos e provar de suas angústias.

É importante trazer à baila a discussão proposta por Resende (2014) sobre narrativa, cultura e alteridade, tomando como pano de fundo o conflito afro-muçulmano no Brasil, centrado na Rebelião dos Malês (1835). Importa destacar que os espaços de consolidação e a divisão de categorias nós/eles são formulados como constructos históricos, teóricos e discursivos. As ideias apontadas por Resende se constituem como perspectivas para se pensar a localização do sujeito subalterno no cerne da prática jornalística - principalmente, porque a realidade do outro contrastante possibilita a investigação sobre o homem comum e sobre os rastros de sua biografia - no âmbito social, cultural e histórico:

Assim vemos que, os processos de entrelaçamento de culturas e de invenção do outro, são, juntos, constitutivos de um mesmo problema; eles são o resultado de uma luta que se trava entre o esforço de nomeação - e, portanto, de sustentação de identidades - e de ressignificação, uso e criação de elos de identificação. Entre as demandas e as delicadezas é que a cultura aparece como um tecido feito de restos, como dirá Certeau (1995), algo vivo, fruto de um fiar constante que, no escopo das experiências e das narrativas, reluta em não se reduzir a um gesto ou outro (RESENDE, 2014, p. 217).
Resende traz ao centro do debate Homi Bhabha para ressaltar que a partir da compreensão de um processo de sobreposição de narrativas, pode-se compreender a cultura como instância de negociação e conflito:

\begin{abstract}
Um processo complexo que dá lugar a um movimento paradoxal tomado por jogos de entrelaçamento de culturas e esforços de invenção do outro. Sob esta perspectiva, o objetivo central desta reflexão é dar a ver esses gestos, de modo a reconhecer os marcadores de diferenças como parte deste movimento - e este é o problema aqui relevante - que acontece com e a despeito (d)as materialidades e (d)as geopoliticas dominantes que afastam culturas, apartam sujeitos e decodificam modos de vida (RESENDE, 2014, p. 208).
\end{abstract}

Desse modo, como lembra Santos (2014), a análise micro-histórica emerge como um percurso metodológico que possibilita a construção de uma "história dos sistemas comunicativos, a partir da trajetória individual" (SANTOS, 2014, p. 2), fomentando a emergência do cotidiano e do diálogo com os sujeitos comuns - cujas histórias foram subalternizadas ao longo do tempo. Os estudos de Carlo Ginzburg permitem a arquitetura de uma modalidade de história centrada nos aspectos individuais e em sua relação com os outros sujeitos.

Ginzburg critica frontalmente as visões aristocráticas de cultura - instituída como atributo das classes hegemônicas. Para o autor de $O$ queijo e os vermes, a cultura popular é gerada, reproduzida e renovada cotidianamente pelas classes subalternas, em um processo de constante circularidade cultural ${ }^{8}$.

Brum (2011) ilustra que sem o movimento detido de observação - o exercício da pauta seria malogrado. Ao se deter na escuta e não nas perguntas, foi possivel à autora de $A$ vida que ninguém vê constatar que Ailce nunca pronunciava a palavra câncer. Ao verificar o apagamento do termo nas conversas que

\footnotetext{
8 O conceito de "circularidade cultural" proposto por Ginzburg relaciona-se aos postulados advindos de Mikhail Bakhtin e de seu Círculo. O pressuposto aponta para a possibilidade de se investigar a cultura como algo plural e complexo. Silva (2017) assevera que o termo corrobora para a "presença de uma comunicabilidade que transcorria de maneira dialógica, circular e, por conseguinte, de forma mútua e reciproca [...] entre a cultura das classes subalternas e das dominantes existentes em uma Europa pré-industrial" (SILVA, 2017, p. 73). Nesse sentido, Carlo Ginzburg foge da dicotomia "cultura oficial" versus "cultura popular", optando pela interação e circularidade entre os diferentes campos enunciativos.
} 
mantinha com a merendeira, Brum compreendeu que a palavra esboçava um sentido que Ailce desejava esconder. O vocábulo em si dizia mais sobre finitude do que sobre a vida - e Ailce, apesar do câncer das vias biliares - era toda vida.

E eu nunca pronunciei a palavra câncer. Se eu chegasse perguntando - "Mas e o seu câncer..." - eu jamais saberia que ela nunca pronunciou essa palavra. Então, esse é o cuidado que a gente tem que ter na escuta: as nossas perguntas não atropelarem, tanto os sentimentos do entrevistado - colocar questões para as quais ele não está preparado - como fazer com que ele conte a história com as nossas palavras e não com as dele.

Porque se eu falasse em "câncer", talvez ela falasse em "câncer" e eu nunca saberia que essa não era a palavra, que essa era uma palavra impossivel para ela. Eu nunca falei em morte antes que ela falasse de morte. Se eu tivesse já chegado falando da morte, eu não saberia que ela só falava da vida. O que ela mais falava era em comida, que é uma grande afirmação da vida. Então, nessa reportagem especificamente, isso fica muito claro (BRUM, 2011, p. 316-317).

O exercício meticuloso da escuta exige da repórter um posicionamento delicado, afetivo, terno. Isso é necessário por dois motivos: primeiro, para não inundar o entrevistado com perguntas. Segundo, para que a personagem utilize suas próprias palavras, o seu léxico particular e haja a possibilidade de vir à torna os elementos de sua cultura, do seu cotidiano e de sua vida. Desse modo, evita-se que o jornalista "invada" o território do entrevistado com sua visão de mundo e afete o modo de a personagem reportar aos seus pensamentos e à sua história.

Essa escuta cuidadosa pode ser constatada nos detalhes e no conjunto de informações coletadas por Eliane sobre Ailce. Como foi enunciado, não se trata apenas de contar, mas de compreender como se organizam as lacunas e os sentidos de uma vida.

Ailce deixou a casa dos pais aos dezoito anos. Devagar São Romão foi encothendo diante de suas ânsias de muther jovem. Parecia até que a cidade. antes tão larga, tinha criado paredes. "Me criei num mundo em que preto era preto, pobre era pobre, fazendeiro era fazendeiro, doméstica era doméstica", diz. "Eu queria ir pra frente, sempre quis conhecer coisas novas."
Escorregou no mapa e desembarcou em Guarulhos, no estado de São Paulo, na casa de um irmão mais velho. $E$ de novo se sentiu confinada. Mudara de geografia, mas não de sina, e para ela os sessenta não foram anos loucos. Ailce foi operária, costureira, moça de fábrica. E foi entre linhas, agulhas e bobinas que teve as primeiras revelações sobre sexo, quando uma colega contou ao voltar da noite de núpcias que não só doía, como ao final jorrava um líquido branco e pegajoso do membro do homem. Ailce arquivou a informação para não fazer cara de surpresa quando sua hora chegasse.

\section{[...]}

Aos 23 anos, ela tomou uma decisão pragmática.

Casou-se com um operário chamado Jaime, irmão de um vizinho, dez anos mais velho. Ele era um rapaz alinhado, que não botava a cabeça fora de casa sem brilhantina, sem um lustro nos sapatos. "Eu não queria mais morar na casa dos outros, queria ter um lugar meu", diz Ailce. "Ele era honesto, trabalhador, andava de terno e gravata, tinha uma familia boa. Casei."

Ailce não poderia saber que moço assim tão distinto teria ganas de beber além da conta. Nem que uma parte considerável do seu futuro seria gasta no destino sempre triste - e sempre tão lugar-comum - de mulher de alcoólatra. No caso de Ailce ainda mais triste porque nada tinha da originalidade que ela planejara para si. Assinou o livro do cartório convicta de que o amor romântico era uma ilusão que não cabia mais no mundo adulto que a esperava. E talvez tenha sido essa a primeira capitulação de Ailce diante dos seus sonhos. Quando adoeceu, há muito a aliança tinha sumido de seu dedo. "Não serve mais", diz. "Está apertada" (BRUM, 2008, p. 391-393).

Verifica-se que o exercício profissional da autora de A vida que ninguém vê é marcado pelo abalo dos estamentos que sustentam o jornalismo hegemônico, permitindo orientar seu fazer, sua subjetividade e seus saberes em direção a uma abertura heuristica da prática.

No fragmento ficam evidenciados os aportes teórico-metodológicos da micro-história. A vida de Ailce problematiza os silêncios e abre a possibilidade para se pensar em novos parâmetros de leitura sobre o cotidiano e sobre os sujeitos. 
O sistema normativo de referência e os repertórios cognitivos da prática jornalistica podem, desse modo, desvelar novos saberes para reportar à realidade. Disso resulta que a existência de Ailce interpela a configuração do relato hegemônico ao possibilitar uma reflexão interpretativa sobre as unidades apensas e sobre as histórias comuns.

Disso resulta que o trinômio "esvaziamento", escuta e olhar determinam uma forma de apuração balizada pelo apagamento das abordagens reducionistas dos contextos socioculturais - possibilitando que a jornalista apareça como articuladora da experiência narrativa - ao subverter a ordem dos manuais de redação e da técnica jornalística. Das bordas da prática observa-se o aparecimento da crítica, do "livro de repórter" e da figura autoral.

Esse movimento, segundo Silva (2018), possibilita o desnudamento dos aspectos subjetivos, a evidenciação dos detalhes que compõem a vida comum e o entendimento aprofundado dos dramas das experiências individuais e coletivas:

Em oposição à noção positivista de objetividade impressa nestes manuais, o sujeito-repórter aparece na narrativa destes profissionais como elemento fundamental no processo cognitivo de interpretação da realidade - vastamente apagado da deontologia dominante. Percebe-se a possibilidade do rigor do método sem que a prática se restrinja ao cumprimento tecnicista e burocrático que, além de apagar o sujeito-repórter, muitas vezes se limita às fontes oficiais e à superfície dos acontecimentos. $\mathrm{O}$ corpo, a intuição, os sentires são parte intrínseca às práticas jornalísticas (SILVA, 2018, p. 10).

Ao se colocar diante da vida de Ailce, Brum põe em prática suas táticas de aproximação com a fonte, marcada pela escuta, pelo esvaziamento e pelo olhar detido às texturas, sons e silêncios. Segundo Marocco (2016), ao se deslocar da relação objetiva estabelecida entre fonte e jornalista, Brum não ocupa o lugar de amiga, mas o da escutadeira que incorpora a repórter.

Assentada sob essa premissa, a autora de $A$ vida que ninguém vê toma o relato jornalístico como possibilidade para se pensar os sujeitos sociais e os diálogos entre narrativas e contextos. Contrapõem-se, portanto, ao jornalismo fincado sob as premissas de neutralidade, imparcialidade e objetividade que não consegue apreender a dinâmica que atravessa o contexto social e age por simplificação.

Fontcuberta (2006) destaca que o relato jornalistico vive na contemporaneidade sob o império dos principios da disjunção, redução e abstração - que em conjunto constituem o que se denomina como "paradigma da simplificação". A autora explica que a forma "atomizada" de reportar aos contextos sociais implica em uma barreira para se compreender a realidade.

Apreende-se, nesse sentido, que a prática jornalística centrada na configuração social, cultural e política, permite a enunciação de um discurso e de uma narração que problematize e complexifique as distintas realidades que compõem o contexto social. Dessa forma, o jornalismo pode ir além dos maniqueísmos, permitindo-se lançar um olhar heurístico sobre os fatos que compõem a realidade social, cultural e histórica.

\section{Considerações finais}

A junção entre jornalismo e micro-história abre a possibilidade de uma sintese mais rica de compreensão e de fusão da história da experiência do cotidiano com tipos mais tradicionais de narrativa - articulando as histórias das pessoas comuns à biografia das classes hegemônicas - em um movimento de circularidade cultural.

Ao inserir novas possibilidades de estudo da realidade e levar para a superfície da reportagem o aparato conceitual por meio do qual os fatos são ordenados no discurso, a micro-história fornece um cabedal de instrumentos que convergem para leituras mais aprofundadas da urdidura do texto jornalístico e de esquadrinhamento do mundo. Nota-se que a obra de Eliane Brum, em estudo, tende a reconstruir novas versões para as histórias das pessoas comuns, sobretudo, para as representações sociais e para a arquitetura do relato jornalístico. 


\section{Referências}

ALSINA, Miquel Rodrigo. A construção da notícia. Tradução de Jacob A. Pierce. Petrópolis: Vozes, 2009

BORRAT, Héctor. Necesidad y riesgo de las fuentes. In: BORRAT, Héctor; FONTCUBERTA, Mar de (org.). Periódicos: sistemas complejos, narradores em interación. Buenos Aires: La Crujía, 2006.

BRUM, Eliane. Eu sou uma escutadeira: entrevista com Eliane Brum. In: MAROCCO, Beatriz. O jornalista e a prática: entrevistas. São Leopoldo: Editora Unisinos, 2012

BRUM, Eliane. A menina quebrada e outras histórias de Eliane Brum. Porto Alegre: Arquipélago Editorial, 2013.

BRUM, Eliane. Meus desacontecimentos: a história da minha vida com as palavras. São Paulo: LeYa, 2014

BRUM, Eliane. Eliane Brum e a arte da escuta. Revista Em Questão, Porto Alegre, n. 1, v. 17, jan./dez. 2011. Entrevista concedida a Agnes Francine de Carvalho Mariano. Disponivel em: https://seer.ufrgs.br/ index.php/EmQuestao/article/view/15047. Acesso em: 20 dez. 2017.

BRUM, Eliane. O filho possivel. Revista Época, São Paulo, 9 abr. 2010. Disponivel em: http://elianebrum. com/reportagens/o-filho-possivel/. Acesso em: 20 jul. 2018.

FONTCUBERTA, Mar de. El periódico en una sociedad compleja. In: BORRAT, Héctor; FONTCUBERTA, Mar de (org.). Periódicos: sistemas complejos, narradores em interación. Buenos Aires: La Crujía, 2006.

GANS, Herbert. Deciding What's News: a study of CBS Evening News, NBC Nightly News, News, Newsweek and Time. New York: Pantheon Books 1979. https://doi.org/10.2307/1955692

GINZBURG, Carlo; PONI, Carlo. O nome e o como: troca desigual e mercado historiográfico. In: GINZBURG, Carlo; PONI, Carlo; CASTELNUOVO, Enrico (org.). A micro-história e outros ensaios. Trad. de António Narino. Rio de Janeiro: Difel-Bertrand Brasil, 1991.

GINZBURG, Carlo. O fio e os rastros. São Paulo: Companhia das Letras, 2007.

GOBBI, Maria Cristina; KONDLATSCH, Rafael. A relação do jornalista com as fontes de informação na era digital. Revista Estudos de Jornalismo, [S. l.], n. 7. dez. 2017. ISSN 2182-7044. Disponivel em: http://www.revistaej.sopcom.pt/ficheiros/ 20180201-ej7_2017.pdf. Acesso em: 10 jan. 2018.

LEVI, Giovanni. Micro-história e história da imigração. In: VENDRAME, Maira Ines et al. (org.). Micro-história, trajetórias e imigração. São Leopoldo: Oikos, 2015. Disponivel em: http://oikoseditora.com.br/ files/Micro-Hist\%C3\%B3ria\%20-\%20E-BOOK.pdf. Acesso em: 30 maio 2016. https://doi.org/10.4013/ htu.2016.203.04

LIMA, Henrique Espada. A micro-história: escalas, indicios e singularidades. Rio de Janeiro: Civilização Brasileira, 2006.
MAROCCO, Beatriz. Ações de resistência no jornalismo: Livro de repórter. Florianópolis: Insular, 2016.

RESENDE, Fernando. Narrativas e conflito afro-muçulmano no Brasil: cultura e luta por desejos e poderes. Revista Matrizes, São Paulo, v. 8, n. 1, jan./jun. 2014. Disponivel em: http://www.matrizes.usp.br/ index.php/matrizes/article/view/311/pdf. Acesso em: 19 fev. 2019.

REVEL, Jacques. Microanálisis y construcción de lo social. In: REVEL, Jacques (org.). Juegos de escalas experiencias de microanálisis. San Martín: Universidad Nacional de General San Martin, 2015. https:// doi.org/10.21840/siic/144544

SANTOS, Andréa Cristiana. A contribuição da micro-história para o campo da comunicação: uma abordagem historiográfica a partir da trajetória de homens comuns. In: CONGRESSO BRASILEIRO DE CIÊNCIAS DA COMUNICAÇÃO, 37., 2014, FOZ do Iguaçu. Anais [...]. Disponivel em: http://Www. intercom.org.br/papers/nacionais/2014/resumos/ Rg-2443-1.pdf. Acesso em: 19 fev. 2019. https://doi. org/10.11606/d.27.2017.tde-05092017-095727

SILVA, Marcia Veiga da. Trajetórias de vida e práticas jornalísticas afeitas à alteridade: a inclusão da subjetividade na subversão dos modos de objetivação do jornalismo. In: ENCONTRO NACIONAL DE PESQUISADORES EM JORNALISMO, 16., 2018, Morumbi. Anais [...]. Disponivel em: http://sbpjor.org. br/congresso/index.php/sbpjor/sbpjor2018/paper/ viewFile/1344/900. Acesso em: 28 jan. 2019. https:// doi.org/10.20873/uft.2447-4266.2018v4n1p398

SILVA, Leonardo Santana da. Carlo Ginzburg: o conceito de circularidade cultural e sua aplicação nos estudos sobre a música popular brasileira.

Revista Augustus, Bonsucesso, v. 22, n. 43, jan./ jun. 2017. Disponivel em: http://apl.unisuam.edu. $\mathrm{br} /$ revistas/index.php/revistaaugustus/article/ view/19811896.2017v22n43p72. Acesso em: 20 jan. 2019 https://doi.org/10.15202/19811896.2017v22n43p 72

TRAQUINA, Nelson. Teorias do jornalismo: a tribo jornalística - uma comunidade interpretativa transnacional. Florianópolis: Insular, 2013.

VELOSO, Maria do Socorro Furtado; PAVAN, Maria Angela. Jornalismo como tessitura do cotidiano na obra de Eliane Brum. In: FREIRE FILHO, João; COELHO, Maria das Graças Pinto (org.). Jornalismo, Cultura e Sociedade: visões do Brasil contemporâneo. Porto Alegre: Sulina, 2014. https://doi.org/10.17771/ pucrio.acad. 30845

VENTURA, Mauro de Souza; ABIB, Tayane Aidar. A notícia como desacontecimento: possibilidades de inovação a partir das narrativas de Eliane Brum. Revista Comunicação Midiática, Bauru, n. 3, v. 10, set./dez. 2015. Disponivel em: http://www2.faac.unesp.br/comunicacaomidiatica/index.php/comunicacaomidiatica/article/viewArticle/667. Acesso em: 5 jan. 2018. https://doi.org/10.5007/1984-6924.2016v13n1p56

ZAMIN, Angela. Apresentação. In: MAROCCO, Beatriz. Ações de resistência no jornalismo: livro de repórter. Florianópolis: Insular, 2016. 
ZAMIN, Angela. Livros de repórter, saberes de entremeio: relatos jornalisticos sobre a cobertura de conflitos. Estudos em Jornalismo e Midia, Florianópolis, n. 2, v. 8, jul./dez. 2011. Disponível em: https://periodicos.ufsc.br/index.php/jornalismo/article/view/ 1984-6924.2011v8n2p389. Acesso em: 13 jan. 2017. https://doi.org/10.5007/1984-6924.2011V8n2p389

ZORZAL, Gabriela. Paradigma indiciário e o campo do jornalismo: possiveis aproximações. Revista Sinais, Vitória, n. 15, jun. 2014. ISSN 1981-3988. Disponivel em: http://periodicos.ufes.br/sinais/article/ view/8598/6049. Acesso em: 10 jan. 2018. https:// doi.org/10.25067/s.v1i21.16678

\section{Beatriz Marocco}

Doutora em Periodismo y Ciencias de La Comunicación pelo Universitat Autònoma de Barcelona - UAB, Espanha (2002). Pesquisadora e professora da Universidade do Vale do Rio dos Sinos (Unisinos), São Leopoldo, Brasil.

\section{Correspondência}

Universidade do Vale do Rio dos Sinos,

Centro de Ciências da Comunicação.

Avenida Unisinos, 950

Cristo Rei

93-022000 - São Leopoldo, RS - Brasil.

\section{Francisco Aquinei Timóteo Queirós}

Doutorando do Programa de Pós-Graduação em Ciências da Comunicação, na linha de pesquisa Linguagem e Práticas Jornalisticas, na Universidade do Vale do Rio dos Sinos (Unisinos), São Leopoldo, Brasil. Professor efetivo do curso de Jornalismo da Universidade Federal do Acre (UFAC).

\section{Correspondência}

Universidade Federal do Acre, Centro de Filosofia e Ciências Humanas - $\mathrm{CFCH}$.

Rodovia BR 364, n 6637 (Km 04)

Distrito Industrial

69915-900 - Rio Branco, AC - Brasil 